\title{
A Novel Environmental Monitoring Strategy for Industrial Safety and Disaster Prevention Management Applications
}

\author{
Zong-Yi Yang, ${ }^{1}$ Chih-Wei Chou, ${ }^{1}$ Wei-Cheng Lin, ${ }^{2}$ \\ Wei-Chun Chen, ${ }^{3}$ and Chi-Min Shu ${ }^{1,2,4^{*}}$ \\ ${ }^{1}$ Center for Process Safety and Industrial Disaster Prevention, National Yunlin University of Science and \\ Technology (YunTech), 123 University Rd., Sec. 3, Douliou, Yunlin 64002, Taiwan, ROC \\ ${ }^{2}$ Doctoral Program, Graduate School of Engineering Science and Technology, YunTech, \\ 123 University Rd., Sec. 3, Douliou, Yunlin 64002, Taiwan, ROC \\ ${ }^{3}$ Bachelor Program in Interdisciplinary Studies, YunTech, \\ 123 University Rd., Sec. 3, Douliou, Yunlin 64002, Taiwan, ROC \\ ${ }^{4}$ Department of Safety, Health, and Environmental Engineering, YunTech, \\ 123 University Rd., Sec. 3, Douliou, Yunlin 64002, Taiwan, ROC \\ (Received April 15, 2019; accepted May 8, 2020)
}

Keywords: industrial safety and disaster prevention management, intelligent environmental monitoring system, monitoring sensor network, desktop/laptop/mobile network, smart user interface

Building an industrial safety and disaster prevention management (ISDPM) system can effectively prevent unforeseen industrial accidents, such as fires, explosions, releases of hazardous chemicals, and leaks of poisonous gases. To prevent disasters caused by the smoldering and spontaneous combustion of hazardous wastes in a hazardous waste storage area, we proposed a novel intelligent environmental monitoring system (IEMS) for ISDPM applications. The proposed IEMS based on the integration of a monitoring sensor network, remote central database server, desktop/laptop/mobile network, and smart user interface has the ability to smartly and automatically help users prevent disasters from occurring. Through using network connections, all of the devices were able to perform real-time actual data transmission directly. Therefore, users could select a communication product from anywhere at any time to scrutinize the details of the overall current ambient environmental information, including surveillance images, thermal images, gas concentrations, air quality, temperature, and humidity. The results obtained with the proposed IEMS in practical field tests suggest its high suitability for use in a wide range of industries.

\section{Introduction}

Owing to the intensive development of sensor technologies, the Internet of Things (IoT), and artificial intelligence (AI) over the last few years, ${ }^{(1-19)}$ industrial safety and disaster prevention management (ISDPM) systems have become smart and automatic (Smart Auto), feeding early warning messages and/or other related information back to the safety management office in real-time before a disaster occurs. Therefore, ISDPM systems play an invaluable and pivotal *Corresponding author: e-mail: shucm@yuntech.edu.tw https://doi.org/10.18494/SAM.2020.2882 
role in maintaining workplace safety, process safety, occupational health, and high production efficiency. Recently, several studies on ISDPM applications have been conducted. ${ }^{(20-31)}$ For example, Boano et al. described the adoption of an industrial wireless temperature sensor deployment technique in an oil refinery for studying the influence of high temperatures and fire prevention. ${ }^{(20)}$ Gomaa et al. depicted a smart wireless radiation sensor network with economical and straightforward deployment designed for environmental radioactivity monitoring and safety assessment in a nuclear power plant. ${ }^{(22)}$ Chraim et al. presented an extensive monitoring network of multiple industrial wireless gas sensors covering a sensitive industrial area in an oil refinery plant used for the detection and localization of gas leaks and explosion prevention. ${ }^{(24)}$ Wang et al. demonstrated a three-level framework together with machine learning to process data collected from wireless sensor nodes in a petrochemical plant for investigating the intelligent prediction of leak points and the safety of production sites. ${ }^{(25)}$ Qiu et al. introduced the uses of a laser module and machine vision for automatic and real-time tunnel deformation monitoring and safety monitoring requirements in tunnel traffic infrastructure construction. ${ }^{(28)}$

To meet the demand for various monitoring applications, we can custom-make appropriate ISDPM systems by matching multiple environmental monitoring modules (EMMs), central database servers, smart user interfaces, and disaster prevention devices. Then, further optimizing the ISDPM system will enhance the system performances substantially. ISDPM systems, therefore, have numerous compelling advantages as follows. (1) They are IoT-based Smart Auto monitoring and data-recording systems. (2) They have an easy-to-use platform, a user-friendly interface, and powerful monitoring functions. (3) They have custom smart actions through the use of monitoring data analytics to control smart power strips automatically. (4) They can be installed and positioned and put into operation readily and quickly in diverse industrial environments. (5) They can also boost overall economic growth and competitiveness of the industry to increase employee willingness to work.

In this study, we proposed a novel IoT-based intelligent environmental monitoring system (IEMS), as shown in Fig. 1, to prevent major fires and explosions from the smoldering and spontaneous combustion of hazardous wastes in a hazardous waste storage area. A practical

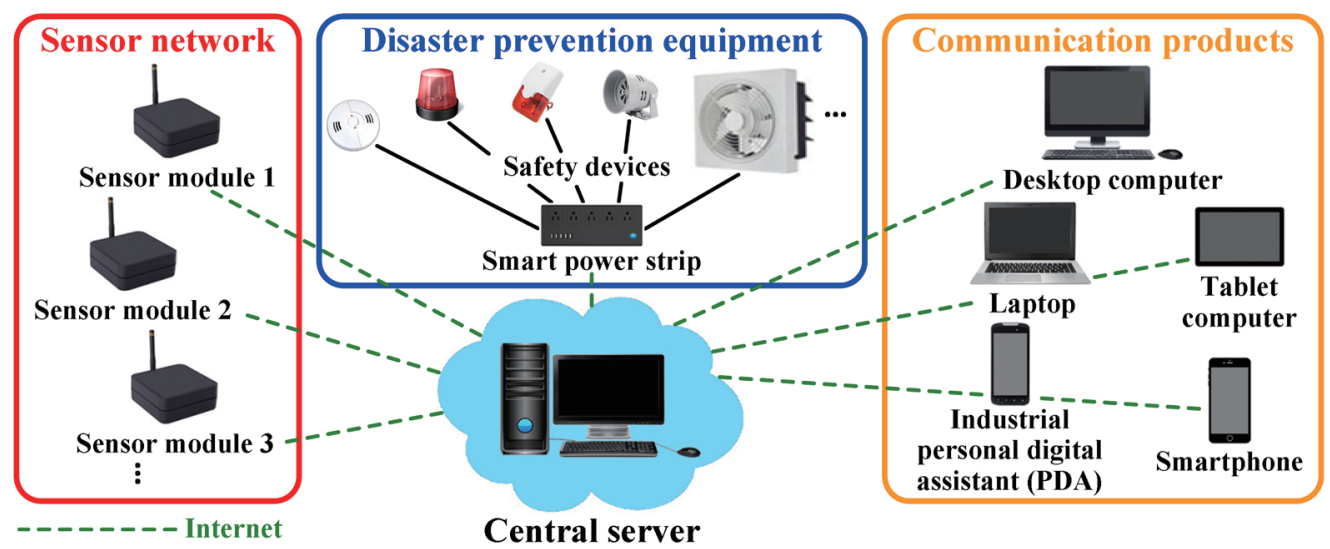

Fig. 1. (Color online) Novel environmental monitoring strategy based on the IoT. 
field test of the IEMS was performed at the Environmental Protection Technology Company of Taiwan. The IEMS architecture primarily integrated a monitoring sensor network, remote central database server, desktop/laptop/mobile network, and smart user interface. To meet the safety requirements of a whole area, we configured appropriate ambient EMMs capable of observing surveillance images, thermal images, gas concentrations, air quality, temperature, and humidity. We also installed a remote central database server that could analyze, process, store, and manage the actual real-time sensing data received from the sensor network, and then supply the environmental information to desktop/laptop/mobile communication products almost simultaneously. The data transmission of all devices was conducted immediately over a connected network. Thus, users could see the real-time environmental information anywhere and anytime from a remote central database server as long as they connected one of these communication products to the database server via a static internet protocol (IP) address.

\section{Experimental Methods and Materials}

Our customizable approach to integrating appropriate EMMs was to develop and build a remote real-time IEMS divided into five major steps. First, we had to understand clearly the complete operating procedures of the company, involving all equipment, materials, and operations, to find out where long-term monitoring is essential. Second, we attentively explored how to build an effective monitoring system among equipment's operational states, workplace environments, and work-related behaviors together with relevant staff. Third, we configured the necessary monitoring modules with respect to the identified danger zones. Fourth, we developed a remote central database server, smart user interface, and other specialized devices. Finally, we executed functional tests of the proposed customizable IEMS (see Sect. 3).

\subsection{Considerations}

In this study, we developed and built an optimal IEMS at the Environmental Protection Technology Company in Taiwan, which served as an ISDPM system and application. Photographs of the company site are given in Fig. 2. The company is Taiwan's largest enterprise carrying out environmental testing, environmental protection engineering, professional industrial waste treatment, recovery, and recycling. The company employs cutting-edge techniques in its operations management system, computer control center and monitoring system, and energy-efficient incineration facilities. The company mainly deals with the collection, physicochemical treatment, solidification, incineration, and landfill of hazardous waste and handles a variety of wastes, including biomedical and health-care wastes, toxic chemical wastes, hazardous industrial wastes from manufacturing, general industrial wastes, and mixed metal scrap.

In the hazardous waste disposal method of the company before physicochemical treatment or incineration, hazardous wastes are randomly placed in a hazardous waste storage area and generally placed into waste storage tanks/containers and/or on the floor. However, hazardous wastes, regardless of whether solid, semisolid, or liquid, have many uncertainties in their 


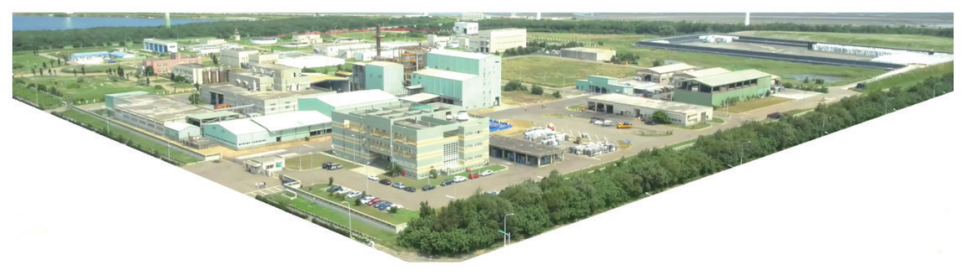

(a)

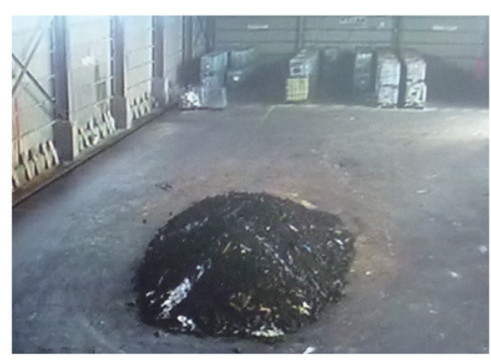

(b)

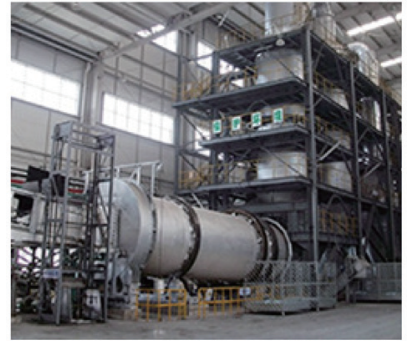

(c)

Fig. 2. (Color online) Photographs of the Environmental Protection Technology Company in Taiwan. (a) Bird's-eye view of the entire site. (b) Hazardous waste storage area. (c) Energy-efficient incineration facilities.

substances, mixtures, materials, and dopant concentrations, and occasionally cause disastrous accidents. ${ }^{(32-37)}$ Whether these wastes are stored for the long-term or short-term, in some cases, solid or semisolid wastes can result in spontaneous combustion, causing major fires. Similarly, heavy metal liquid wastes such as those from semiconductor manufacturing plants, printed circuit board manufacturing plants, and chemical plants, can often react with each other, leading to fires and explosions caused by thermal runaway reactions. Even if there are no explosions or fires, these wastes generate invisible noxious gases and harmful volatile organic compounds (VOCs), resulting in poor air quality. Accordingly, we focused on the most commonly used hazardous waste storage area to demonstrate the customizable IEMS.

\subsection{Building blocks}

The proposed IEMS architecture consisted of four essential parts: (a) a monitoring sensor network, (b) a remote central database server, (c) a desktop/laptop/mobile network, and (d) a smart user interface. Table 1 summarizes the performances of EMMs that we have matched and tested for satisfying the safety requirements of the hazardous waste storage area.

To ensure that users could view complete, clear, accurate, and reliable environmental information remotely and in a timely manner, the locations of the EMMs were significant, and thus the impact of environmental constraints was considered before installing and positioning the EMMs. Figure 3 illustrates the positions of the EMMs and disaster prevention devices in the hazardous waste storage area. The users were able to choose one communication product (see Fig. 1) to see the real-time environmental monitoring information from the remote central database server, including video surveillance images, thermal images, VOCs, particulate matter 
Table 1

(Color online) Summary of EMM performances.

\begin{tabular}{|c|c|c|c|c|}
\hline Name & Photo & Model & Target & Reference value \\
\hline $\begin{array}{l}\text { HIKVISION IR } \\
\text { PTZ speed dome } \\
\text { network camera }\end{array}$ & & $\begin{array}{l}\text { DS-2DE7220IW-AE } \\
\text { 2.0MP }\end{array}$ & $\begin{array}{c}\text { Safety } \\
\text { monitoring }\end{array}$ & $\begin{array}{l}\text { Pixel resolution: } 1920 \times 1080 \\
\text { Frame rate: } 60 \mathrm{~Hz}, 30 \mathrm{fps} \\
\text { Optical zoom: } 20 \times \\
\text { Focal length: } 4.7-94.0 \mathrm{~mm} \\
\text { Focus distance: } 10-1000 \mathrm{~mm} \\
\text { IR distance: } 150 \mathrm{~m} \\
\end{array}$ \\
\hline FLIR IR TIC & & A310 & Temperature & $\begin{array}{l}\text { Pixel resolution: } 320 \times 240 \\
\text { Frame rate: } 30 \mathrm{~Hz}, 30 \mathrm{fps} \\
\text { Range: }-20-120^{\circ} \mathrm{C}, 0-350{ }^{\circ} \mathrm{C} \\
\text { Accuracy: } \pm 2.0^{\circ} \mathrm{C}\end{array}$ \\
\hline $\begin{array}{l}\text { Customizable RTD } \\
\text { module }\end{array}$ & & PT100 (inside); KTC37 & Temperature & $\begin{array}{c}\text { Range: }-200-600^{\circ} \mathrm{C} \\
\text { Resolution: } 0.1{ }^{\circ} \mathrm{C} \\
\text { Accuracy: } \pm 0.15^{\circ} \mathrm{C} \\
\end{array}$ \\
\hline \multirow{2}{*}{$\begin{array}{l}\mathrm{JNC} \text { smart indoor } \\
\text { air quality detector }\end{array}$} & & \multirow{2}{*}{ SD } & VOCs & $\begin{array}{c}\text { Range: } 0-10 / 100 \mathrm{ppm} \\
\text { Resolution: } 0.01 \mathrm{ppm} \\
\text { Accuracy: } \pm 10 \%\end{array}$ \\
\hline & & & $\mathrm{PM}_{2.5}$ & $\begin{array}{c}\text { Range: } 0-600 \mu \mathrm{g} / \mathrm{m}^{3} \\
\text { Resolution: } 0.1 \mu \mathrm{g} / \mathrm{m}^{3} \\
\text { Accuracy: } \pm 10 \mu \mathrm{g} / \mathrm{m}^{3} \pm 5 \%\end{array}$ \\
\hline $\begin{array}{l}\text { ICP DAS high- } \\
\text { accuracy smart } \\
\text { EMM }\end{array}$ & & $\begin{array}{l}\text { DL-100TM485P; M-7005 } \\
\text { WISE-5231 }\end{array}$ & $\begin{array}{l}\text { emperature and } \\
\text { RH }\end{array}$ & $\begin{array}{l}\text { Temp. range: }-20-60{ }^{\circ} \mathrm{C} \\
\text { RH range: } 0-100 \% \mathrm{RH} \\
\text { Temp. resolution: } 0.1{ }^{\circ} \mathrm{C} \\
\text { RH resolution: } 0.1 \% \mathrm{RH} \\
\text { Temp. accuracy: } \pm 0.4{ }^{\circ} \mathrm{C} \\
\text { RH accuracy: } \pm 3.0 \% \mathrm{RH}\end{array}$ \\
\hline
\end{tabular}

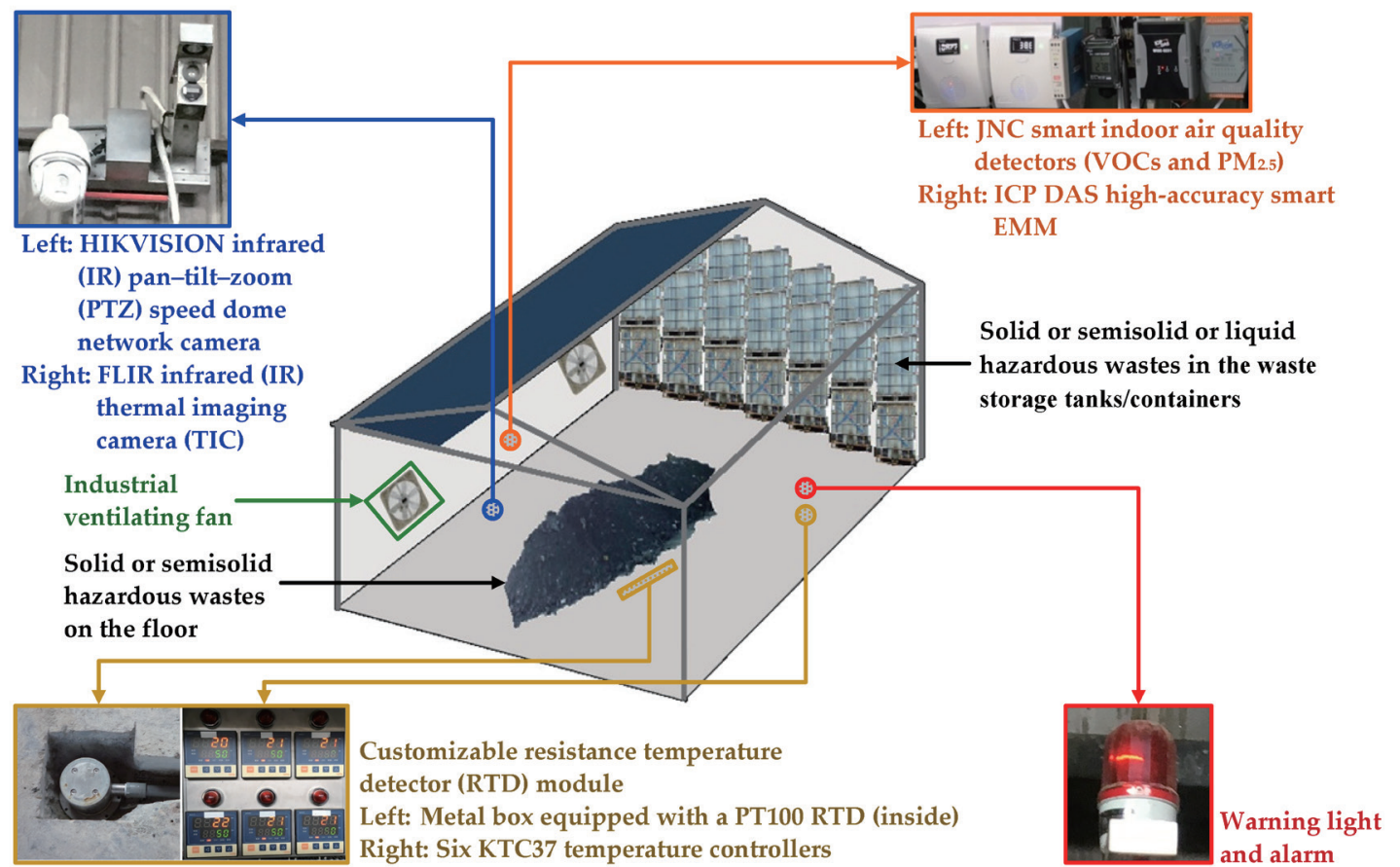

Fig. 3. (Color online) Positions of EMMs and disaster prevention devices in the hazardous waste storage area. 
$2.5\left(\mathrm{PM}_{2.5}\right)$, temperature, and humidity. The data transmission of all devices was implemented directly by employing transmission control protocol (TCP)/IP and/or wireless fidelity (Wi-Fi) and/or fourth-generation (4G) long-term evolution (LTE) network modules. To consider the overall cost-effectiveness of the proposed customizable IEMS, we tried to strike an optimal balance between quality and price. Each of the essential parts of the system is described in detail as follows.

\section{a. Monitoring sensor network}

All EMMs were efficiently deployed at proper places to fully cover the entire space and high-risk targets for long-term monitoring.

- HIKVISION infrared (IR) pan-tilt-zoom (PTZ) speed dome network camera and FLIR IR thermal imaging camera (TIC): We mounted the HIKVISION IR PTZ speed dome network camera along with the FLIR IR TIC at the same positions high on the interior wall near the center of the left-hand vertical wall to monitor the safety behaviors of the whole hazardous waste storage area and the surface temperatures of hazardous wastes, respectively.

- Customizable resistance temperature detector (RTD) module: We customized the RTD module, which comprised six customizable metal boxes and six temperature controllers, where each metal box was equipped with a PT100 RTD, to sense temperatures in the bottom part of hazardous wastes. Next, we embedded six customizable metal boxes on the surface of the indoor floor and installed six temperature controllers at a low position near the center of the interior wall of the front end vertical wall. Mathematically, the relationship between the resistance and temperature of the PT100 RTD can be expressed as

$$
R_{T}=R_{0}\left[1+\alpha_{1} T_{R T D}+\alpha_{2} T_{R T D}^{2}+\alpha_{3} T_{R T D}^{3}+\cdots+\alpha_{n} T_{R T D}^{n}\right]
$$

where $R_{T}$ is resistance at $T_{R T D}{ }^{\circ} \mathrm{C}, R_{0}$ is nominal resistance, which is equal to $100 \Omega$ at $0{ }^{\circ} \mathrm{C}$, and the parameters $\alpha_{1}, \alpha_{2}, \alpha_{3}, \ldots, \alpha_{n}$ are PT100 RTD temperature coefficients of resistance. Since the $\operatorname{sum}\left[\alpha_{3} T_{R T D}^{3}+\alpha_{4} T_{R T D}^{4}+\cdots+\alpha_{n} T_{R T D}^{n}\right]$ is relatively small compared with $\left[1+\alpha_{1} T_{R T D}+\alpha_{2} T_{R T D}^{2}\right]$, Eq. (1) can be simplified and approximately reformulated as

$$
R_{T} \approx R_{0}\left[1+\alpha_{1} T_{R T D}+\alpha_{2} T_{R T D}^{2}\right]
$$

The temperature coefficients $\alpha_{1}$ and $\alpha_{2}$, respectively, were $3.9 \times 10^{-3}$ and $-5.8 \times 10^{-7}$ in this study. Because the customizable RTD module has a temperature difference, $\Delta T$, between the metal box surface and the interior, which can be determined by calibration, the actual temperature can be derived as

$$
T_{R T D-a c} \approx T_{R T D}+\Delta T \text {. }
$$

- JNC smart indoor air quality detectors: We positioned two JNC smart indoor air quality detectors both at low positions near the center of the interior wall of the back end vertical wall 
as close as possible to each other to detect the VOCs and $\mathrm{PM}_{2.5}$ within the hazardous waste storage area. The concentration of VOCs can be estimated using

$$
C_{V O C S}(t)=C_{0}+\left(\frac{E F}{V R}\right)\left(1-e^{-\frac{V R}{V} t}\right)
$$

where $C_{V O C s}(t)\left(\mathrm{mg} / \mathrm{m}^{3}\right)$ is the concentration of VOCs at $t(\mathrm{~h}), C_{0}\left(\mathrm{mg} / \mathrm{m}^{3}\right)$ is the initial concentration of VOCs at $t=0, E F(\mathrm{mg} / \mathrm{h})$ is total VOC emission fluxes from hazardous wastes, and $V R\left(\mathrm{~m}^{3} / \mathrm{h}\right)$ and $V\left(\mathrm{~m}^{3}\right)$ are air ventilation rate and volume, respectively, of the hazardous waste storage area. For long-term storage of the same wastes, assuming time $(t)$ approaches infinity, Eq. (4) can be approximated as follows:

$$
C_{V O C S} \approx C_{0}+\left(\frac{E F}{V R}\right)
$$

Equation (5) provides a means of estimating $C_{V O C S}$ as a steady-state concentration. Note that the unit of measurement for VOCs on the JNC smart indoor air quality detector is ppm (parts per million) and $1 \mathrm{ppm}=3.23 \mathrm{mg} / \mathrm{m}^{3}$. In addition, the concentration of $\mathrm{PM}_{2.5}$ can be mathematically calculated through the following formula:

$$
C_{P M 2.5, \text { in }}=\frac{E R p}{E R+k} C_{P M 2.5, \text { out }}+\frac{G R}{V(E R+k)}
$$

where $C_{P M 2.5, \text { in }}\left(\mu \mathrm{g} / \mathrm{m}^{3}\right)$ and $C_{P M 2.5, \text { out }}\left(\mu \mathrm{g} / \mathrm{m}^{3}\right)$, respectively, are indoor and outdoor $\mathrm{PM}_{2.5}$ concentrations, $E R(1 / \mathrm{h})$ is air exchange rate, $p$ is $\mathrm{PM}_{2.5}$ penetration factor, and $k(1 / \mathrm{h})$ and $G R(\mu \mathrm{g} / \mathrm{h})$ are, respectively, decay rate and generation rate of $\mathrm{PM}_{2.5}$ for the hazardous waste storage area.

- ICP DAS high-accuracy smart EMM: We placed the ICP DAS high-accuracy smart EMM, which comprised a remote temperature and humidity data logger, a thermistor-to-digital converter, and an intelligent expandable multifunction industrial IoT controller, near the two JNC smart indoor air quality detectors to measure air temperature and relative humidity (RH).

\section{b. Remote central database server}

The database server was assigned a preset static IP address and was primarily responsible for analyzing, processing, storing, and managing all actual real-time environmental monitoring data sent by nodes in the monitoring sensor network, and also served as the web server for the smart user interface. The database server almost simultaneously supplied the users with observation results of the ambient environment through the smart user interface. Both the HIKVISION iVMS-4200 versatile video management software and the FLIR IR Monitor software were installed on the database server to display surveillance images and thermal images on the communication product for users to view. Through analysis of the entire environmental monitoring data, the database server could intelligently control smart power strips to run corresponding disaster prevention equipment, such as the alarm system, warning 
light, industrial ventilating fan, the window opening/closing mechanism, and the automatic fire suppression system, according to the given parameter set on the smart user interface. For example, if an abnormal condition occurs that is found by comparing the monitoring data with the given parameters, the early warning message will appear on the smart user interface to alert users, and the alarm system and the warning light will be triggered automatically by controlling the smart power strips. The database server, however, was the most critical equipment, which had an intelligent management platform that was programmed to set up and control the remote equipment.

\section{c. Desktop/laptop/mobile network}

There were a few communication products that could be selected here to pay close attention to the working environment and safety behaviors of the hazardous waste storage area, such as a desktop computer, a laptop computer, an industrial personal digital assistant (PDA), a tablet computer, or a smartphone. Therefore, users can scrutinize the details of overall real-time environmental information anywhere and anytime, as long as their communication product is connected to the remote central database server static IP address. For example, if the hazardous waste storage area has any abnormalities, users can instantly see the early warning message on the smart user interface from the database server. Moreover, by logging in to the remote browser, administrators could manage the smart user interface.

\section{d. Smart user interface}

The smart user interface was designed and implemented with a focus on having a centralized, clean, and easy-to-use platform. The administrators could create, manage, and set up custom-smart-action programs and threshold parameters for automatic remote control capabilities on the smart user interface. For instance, if the VOCs, $\mathrm{PM}_{2.5}$, or temperature is considered unsatisfactory in the hazardous waste storage area, industrial ventilating fans will be automatically started by running custom-smart-action programs along with controlling smart power strips, through the analysis of the entire environmental monitoring data. Moreover, suitable threshold parameter values could be defined by the administrator to reflect changes in environmental factors.

\section{Experimental Results in Practical Field}

In this section, we summarize our practical field test results of the customizable IEMS to estimate and test the performances and functionalities experimentally. All of the textual data and graphical files were recorded and stored in the central database server, which was positioned in the safety management office of the company. The flowchart of the IEMS operation is shown as Fig. 4.

In a small-scale fire test in the hazardous waste storage area, the HIKVISION network camera provided users with a real-time remote image, as shown in Fig. 5, enabling them to inspect and manage the overall safety behaviors of containing wastes, equipment, environments, and people. Figure 6 shows a remote real-time thermal image of the small-scale fire as seen with the FLIR IR TIC and also shows the temperature alarm during the period when high temperatures were detected. 


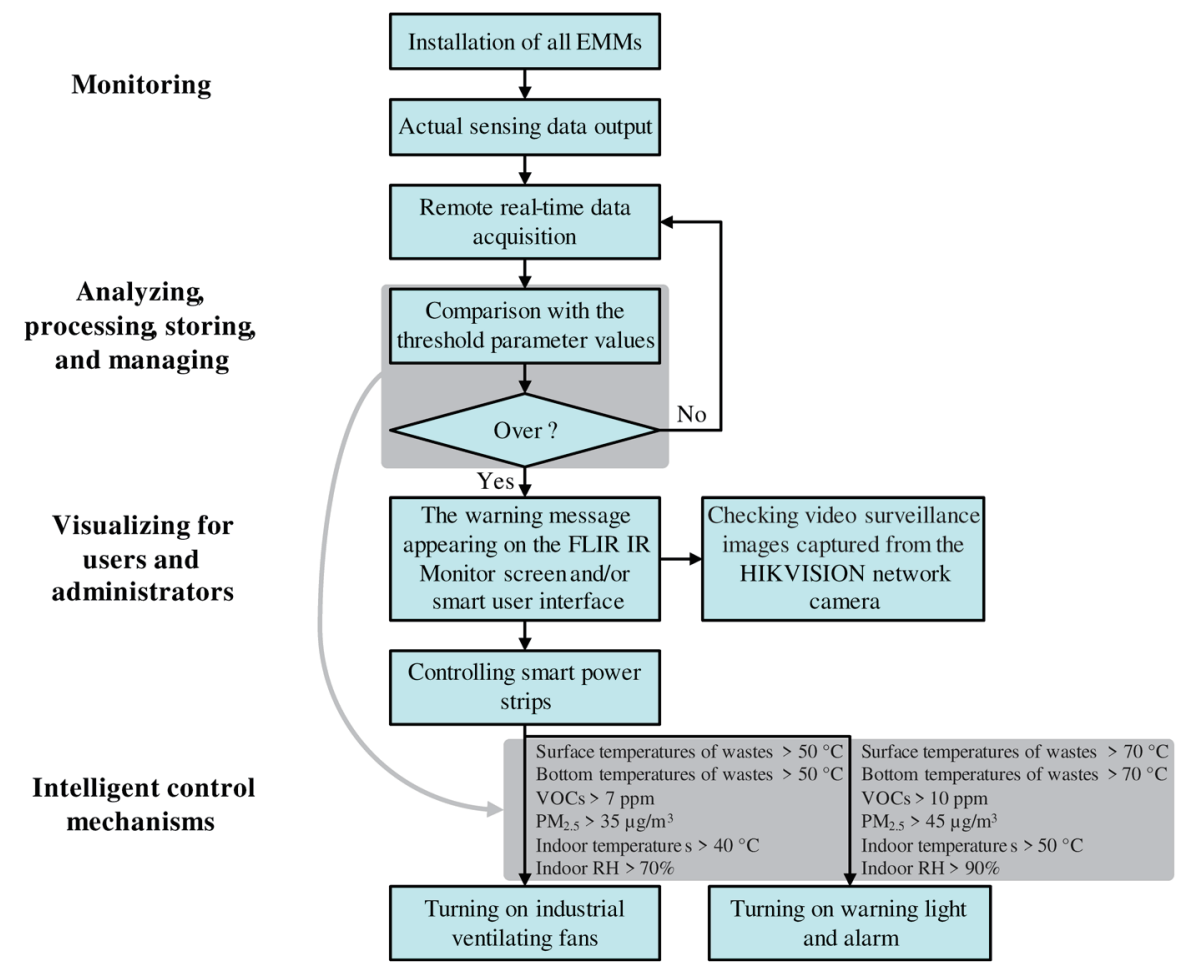

Fig. 4. (Color online) Flowchart of the customizable IEMS operation.

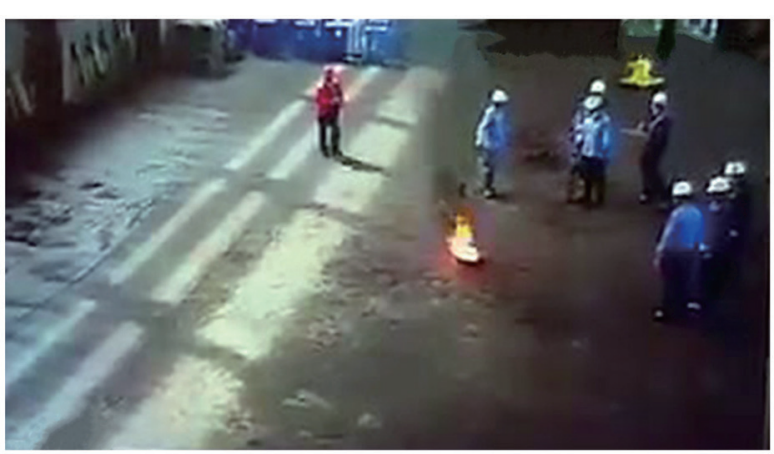

Fig. 5. (Color online) Video surveillance image of field test.

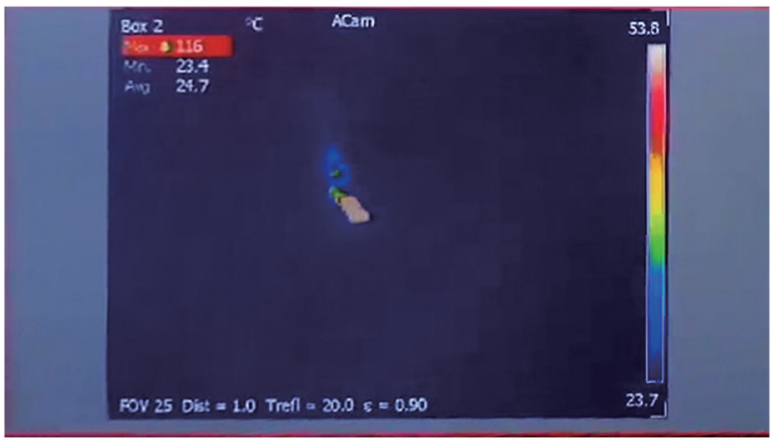

Fig. 6. (Color online) Thermal imaging of surface temperature distribution of field test.

Table 2 lists the maximum, minimum, and average temperatures measured by the customizable RTD module over different days in summer and winter after calibrating the temperature difference. These values were read, analyzed, and applied by the smart user interface.

The smart user interface shown in Fig. 7 was developed using LabVIEW software and presented the VOCs, $\mathrm{PM}_{2.5}$, temperature, and $\mathrm{RH}$ in real-time. These measured values were updated every $10 \mathrm{~s}$, and the average value of each parameter was updated every $5 \mathrm{~min}$. Suitable threshold values of the measured parameters were defined on the smart user interface directly by the administrators. Figure 8 illustrates the remote real-time monitoring platform displayed on a smartphone. 
Table 2

Temperature values measured by customizable RTD module after calibrating the temperature difference.

\begin{tabular}{|c|c|c|c|c|c|c|c|c|c|c|c|}
\hline \multirow{2}{*}{$\begin{array}{l}\text { Node } \\
\text { number }\end{array}$} & & \multicolumn{5}{|c|}{ Summer in Taiwan } & \multicolumn{5}{|c|}{ Winter in Taiwan } \\
\hline & & Day 1 & Day 2 & Day 3 & Day 4 & Day 5 & Day 1 & Day 2 & Day 3 & Day 4 & Day 5 \\
\hline \multirow{3}{*}{1} & $\operatorname{Max} .\left({ }^{\circ} \mathrm{C}\right)$ & 30 & 31 & 34 & 34 & 32 & 21 & 20 & 21 & 17 & 17 \\
\hline & Min. $\left({ }^{\circ} \mathrm{C}\right)$ & 25 & 25 & 25 & 26 & 26 & 18 & 18 & 17 & 16 & 14 \\
\hline & Avg. $\left({ }^{\circ} \mathrm{C}\right)$ & 29 & 28 & 29 & 29 & 28 & 19 & 19 & 18 & 16 & 15 \\
\hline \multirow{3}{*}{2} & $\operatorname{Max} .\left({ }^{\circ} \mathrm{C}\right)$ & 30 & 31 & 35 & 33 & 33 & 22 & 21 & 21 & 18 & 17 \\
\hline & Min. $\left({ }^{\circ} \mathrm{C}\right)$ & 26 & 25 & 25 & 26 & 26 & 18 & 18 & 17 & 16 & 14 \\
\hline & Avg. $\left({ }^{\circ} \mathrm{C}\right)$ & 29 & 28 & 29 & 29 & 28 & 19 & 19 & 18 & 17 & 16 \\
\hline \multirow{3}{*}{3} & $\operatorname{Max} .\left({ }^{\circ} \mathrm{C}\right)$ & 31 & 31 & 35 & 33 & 33 & 22 & 21 & 22 & 18 & 18 \\
\hline & Min. $\left({ }^{\circ} \mathrm{C}\right)$ & 26 & 26 & 25 & 26 & 25 & 18 & 18 & 17 & 16 & 14 \\
\hline & Avg. $\left({ }^{\circ} \mathrm{C}\right)$ & 29 & 28 & 29 & 29 & 29 & 19 & 19 & 19 & 17 & 16 \\
\hline \multirow{3}{*}{4} & $\operatorname{Max} .\left({ }^{\circ} \mathrm{C}\right)$ & 31 & 30 & 34 & 33 & 32 & 23 & 22 & 22 & 18 & 19 \\
\hline & Min. $\left({ }^{\circ} \mathrm{C}\right)$ & 26 & 26 & 25 & 26 & 26 & 18 & 18 & 17 & 16 & 15 \\
\hline & Avg. $\left({ }^{\circ} \mathrm{C}\right)$ & 29 & 28 & 29 & 29 & 28 & 19 & 19 & 19 & 17 & 17 \\
\hline \multirow{3}{*}{5} & $\operatorname{Max} .\left({ }^{\circ} \mathrm{C}\right)$ & 31 & 30 & 33 & 34 & 33 & 22 & 22 & 22 & 18 & 18 \\
\hline & Min. $\left({ }^{\circ} \mathrm{C}\right)$ & 26 & 26 & 25 & 25 & 25 & 18 & 18 & 17 & 16 & 15 \\
\hline & Avg. $\left({ }^{\circ} \mathrm{C}\right)$ & 29 & 28 & 29 & 28 & 29 & 19 & 19 & 19 & 17 & 16 \\
\hline \multirow{3}{*}{6} & $\operatorname{Max} .\left({ }^{\circ} \mathrm{C}\right)$ & 30 & 30 & 33 & 33 & 32 & 22 & 21 & 21 & 18 & 18 \\
\hline & Min. $\left({ }^{\circ} \mathrm{C}\right)$ & 25 & 25 & 26 & 26 & 25 & 18 & 18 & 17 & 16 & 14 \\
\hline & Avg. $\left({ }^{\circ} \mathrm{C}\right)$ & 29 & 28 & 29 & 29 & 28 & 19 & 19 & 18 & 17 & 16 \\
\hline
\end{tabular}

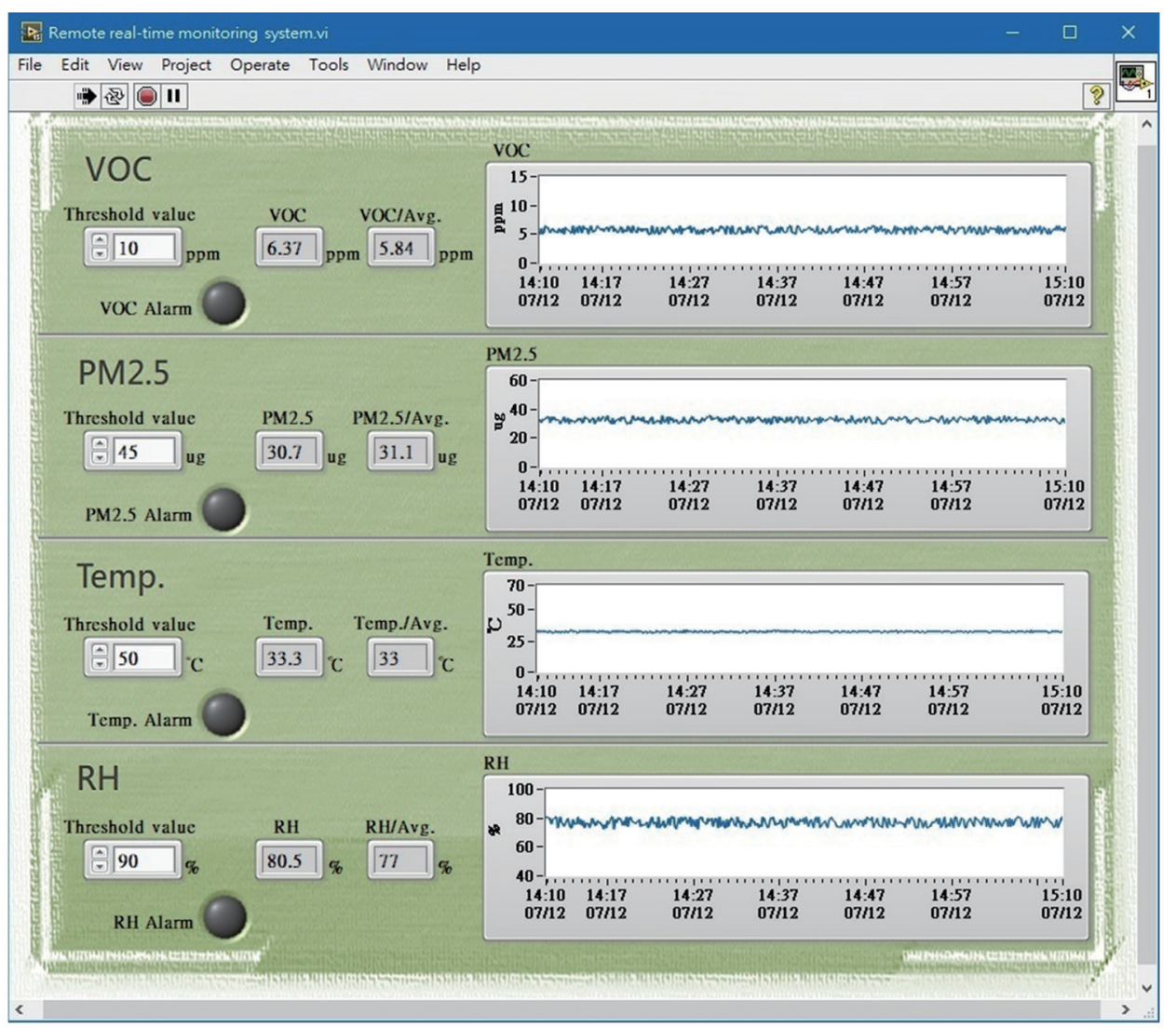

Fig. 7. (Color online) Smart user interface used for showing the VOCs, $\mathrm{PM}_{2.5}$, temperature, and RH. 


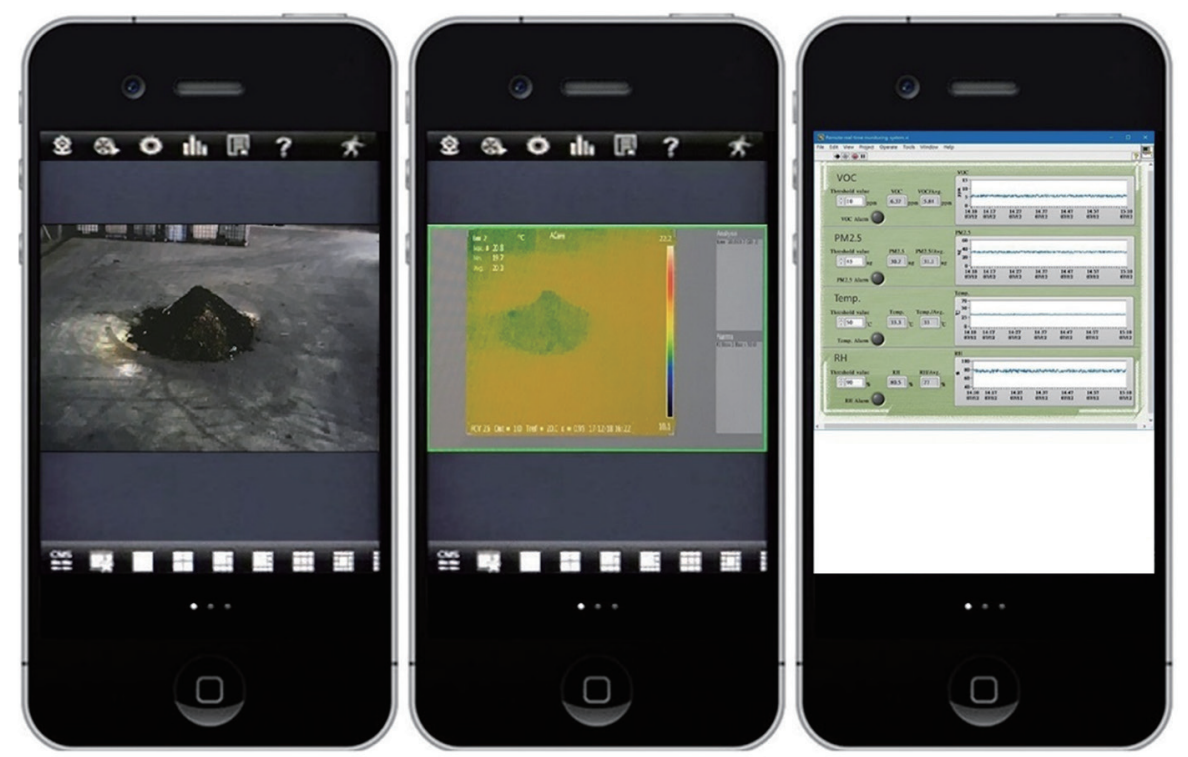

Fig. 8. (Color online) Scheme with the monitoring platform displayed on a smartphone.

\section{Conclusions}

The monitoring capabilities of an IEMS can effectively prevent disaster occurrences and maintain inherent safety if the IEMS has been appropriately equipped with specialized devices associated with the application field. In this study, we have introduced a novel IEMS architecture and a customizable approach along with several EMMs that were selected to meet the overall safety requirements. By virtue of the superior environmental monitoring equipment comprising several EMMs, the remote central database server, and the smart user interface, the proposed customizable IEMS could achieve remote real-time Smart Auto monitoring, recording, managing, and control. Practical field test results of the proposed customizable IEMS were experimentally obtained at the hazardous waste storage area of the Environmental Protection Technology Company in Taiwan to evaluate and validate its performances and functionalities. The presented IEMS architecture with advanced Smart Auto features is exceptionally suitable for ISDPM systems and applications to prevent unforeseen industrial accidents. With its custom-made functions, the customizable IEMS is expected to be highly suitable for use in various industries.

\section{Acknowledgments}

The authors would like to thank the Sunny Friend Environmental Technology Company of Changhua, Taiwan, ROC, for providing the test field and selflessly helping in testing our customizable IEMS, and the Ministry of Education of Taiwan, ROC, for the financial support of this study under grant number 108-A056. 


\section{References}

1 P. Corke, T. Wark, R. Jurdak, W. Hu, P. Valencia, and D. Moore: Proc. IEEE 98 (2010) 1903. https://doi. org/10.1109/JPROC.2010.2068530

2 P. Turaga and Y. A. Ivanov: IEEE Sensors J. 11 (2011) 593. https://doi.org/10.1109/JSEN.2010.2050309

3 C. Schrage, N. Schemm, S. Balkir, M. W. Hoffman, and M. Bauer: IEEE Sens. J. 13 (2013) 2610. https://doi. org/10.1109/JSEN.2013.2258009

4 S. D. T. Kelly, N. K. Suryadevara, and S. C. Mukhopadhyay: IEEE Sens. J. 13 (2013) 3846. https://doi. org/10.1109/JSEN.2013.2263379

5 Y. Fukuda, M. Q. Feng, Y. Narita, S. Kaneko, and T. Tanaka: IEEE Sens. J. 13 (2013) 4725. https://doi. org/10.1109/JSEN.2013.2273309

6 J.-Y. Shieh, Y.-C. Liao, G.-J. Lioao, and Y.-T. Liou: Int. J. Eng. Technol. Innov. 4 (2014) 260.

7 Q. Chi, H. Yan, C. Zhang, Z. Pang, and L. D. Xu: IEEE Trans. Ind. Inform. 10 (2014) 1417. https://doi. org/10.1109/TII.2014.2306798

8 H. F. Rashvand, A. Abedi, J. M. Alcaraz-Calero, P. D. Mitchell, and S. C. Mukhopadhyay: IEEE Sens. J. 14 (2014) 3955. https://doi.org/10.1109/JSEN.2014.2357030

9 J.-Y. Kim, C.-H. Chu, and S.-M. Shin: IEEE Sens. J. 14 (2014) 4230. https://doi.org/10.1109/JSEN.2014.2359832

10 S. Vidas, P. Moghadam, and S. Sridharan: IEEE Sens. J. 15 (2015) 1145. https://doi.org/10.1109/ JSEN.2014.2360709

11 A. Sudarsono, S. Huda, N. Fahmi, M. U. H. A. Rasyid, and P. Kristalina: Int. J. Eng. Technol. Innov. 6 (2016) 103.

12 H. Sakaino: IEEE Sens. J. 16 (2016) 7564. https://doi.org/10.1109/JSEN.2016.2603524

13 J. Wan, S. Tang, Z. Shu, D. Li, S. Wang, M. Imran, and A. V. Vasilakos: IEEE Sens. J. 16 (2016) 7373. https:// doi.org/10.1109/JSEN.2016.2565621

14 U. Umar, M. U. H. A. Rasyid, and S. Sukaridhoto: Int. J. Eng. Technol. Innov. 8 (2018) 157.

15 D. D. Venuto and G. Mezzina: Sens. 18 (2018) 2126. https://doi.org/10.3390/s18072126

16 S. Lu, W. Wang, S. Wang, and E. C. Hameen: Appl. Sci. 9 (2019) 1768. https://doi.org/10.3390/app9091768

17 D. P. Rubanga, K. Hatanaka, and S. Shimada: Sens. Mater. 31 (2019) 831. https://doi.org/10.18494/ SAM.2019.2154

18 S.-Y. Chen: Sens. Mater. 31 (2019) 1707. https://doi.org/10.18494/SAM.2019.2331

19 W.-L. Hsu, C.-Y. Ho, C.-K. Liang, Y.-C. Shiau, H.-N. Hsieh, and S.-C. Lai: Sens. Mater. 31 (2019) 3465. https:// doi.org/10.18494/SAM.2019.2482

20 C. A. Boano, N. Tsiftes, T. Voigt, J. Brown, and U. Roedig: IEEE Trans. Ind. Inform. 6 (2010) 451. https://doi. org/10.1109/TII.2009.2035111

21 W.-T. Sung and C.-C. Hsu: IET Communications 7 (2013) 1789. https://doi.org/10.1049/iet-com.2013.0266

22 R. I. Gomaa, I. A. Shohdy, K. A. Sharshar, A. S. Al-Kabbani, and H. F. Ragai: IEEE Sens. J. 14 (2014) 4007. https://doi.org/10.1109/JSEN.2014.2357803

23 Y. Zhang, W. Yang, D. Han, and Y.-I. Kim: Sensors 14 (2014) 13149. https://doi.org/10.3390/s140713149

24 F. Chraim, Y. B. Erol, and K. Pister: IEEE Trans. Ind. Inform. 12 (2016) 768. https://doi.org/10.1109/ TII.2015.2397879

25 K. Wang, L. Zhuo, Y. Shao, D. Yue, and K. F. Tsang: IEEE Trans. Ind. Inform. 12 (2016) 2091. https://doi. org/10.1109/TII.2016.2537788

26 A. Gomez, M. Magno, M. F. Lagadec, and L. Benini: IEEE Sens. J. 18 (2018) 459. https://doi.org/10.1109/ JSEN.2017.2716380

27 S. Park, S. H. Park, L. W. Park, S. Park, S. Lee, T. Lee, S. H. Lee, H. Jang, S. M. Kim, H. Chang, and S. Park: Appl. Sci. 8 (2018) 2239. https://doi.org/10.3390/app8112239

28 Z. Qiu, H. Li, W. Hu, C. Wang, J. Liu, and Q. Sun: Appl. Sci. 8 (2018) 2579. https://doi.org/10.3390/app8122579

29 D. Spirjakin, A. Baranov, and S. Akbari: IEEE Sens. J. 18 (2018) 2976. https://doi.org/10.1109/ JSEN.2018.2798925

30 J.-H. Kwon and E.-J. Kim: Sens. Mater. 31 (2019) 579. https://doi.org/10.18494/SAM.2019.2162

31 W.J. Zheng, T.-H. Chang, M. Li, and C.-F. Yang: Sens. Mater. 31 (2019) 3599. https://doi.org/10.18494/ SAM.2019.2504

32 J. I. Chang and C.-C. Lin: J. Loss Prev. Process Ind. 19 (2006) 51. https://doi.org/10.1016/j.jlp.2005.05.015

33 D.-J. Peng, Y.-S. Duh, and C.-M. Shu: J. Loss Prev. Process Ind. 19 (2006) 743. https://doi.org/10.1016/ j.jlp.2006.06.002

34 Y. Shimizu, M. Wakakura, and M. Arai: J. Loss Prev. Process Ind. 22 (2009) 86. https://doi.org/10.1016/ j.jlp.2008.09.003 
35 J.-H. Chi, S.-H. Wu, and C.-M. Shu: J. Hazard. Mater. 171 (2009) 1145. https://doi.org/10.1016/ j.jhazmat.2009.06.125

36 J.-H. Chi, S.-H. Wu, J.-C Charpentier, Y.-P. I, and C.-M. Shu: J. Loss Prev. Process Ind. 25 (2012) 142. https:// doi.org/10.1016/j.jlp.2011.07.008

37 N. Murasawa, H. Koseki, Y. Iwata, and T. Sakamoto: Sustainability 10 (2018) 1116. https://doi.org/10.3390/ su10041116 